\title{
A study on clinico- laboratory parameters of children with scrub typhus in Garhwal region of Himalayan belt
}

\author{
Rathore V. ${ }^{1}$, Imran A. ${ }^{2}$, Pathania M. ${ }^{3}$, Wani G. ${ }^{4}$, Gupta A. ${ }^{5}$ \\ ${ }^{1}$ Dr. Vyas Rathore, Associate Professor, Department of Pediatrics, GDMC Dehradun, ${ }^{2}$ Dr. Ayesha Imran, Senior \\ Resident, Department of Pediatrics, GDMC Dehradun, ${ }^{3}$ Dr. Monika Pathania, Associate Professor, Department of \\ General Medicine, AIIMS Rishikesh , ${ }^{4}$ Dr. Gowhar Wani, Senior Resident, Department of Pediatrics, SMGS Jammu, \\ ${ }^{5}$ Dr. Anumodhan Gupta, DNB Resident, Department of Neonatology, KEM Pune.
}

Corresponding Author- Dr. Ayesha Imran, 23, Shimla Enclave (East), GMS Road, Near Shimla Bypass, Dehradun, Uttarakhand, India. E-mail-dr.ayesha1286@yahoo.co.in

\begin{abstract}
Background: As there is paucity of data on Scrub typhus from Garhwal belt. So, to bridge this gap we conducted this study and tried to bring awareness about Scrub typhus. Methods: This is a descriptive study of 40 patients who were ELISA positive for Scrub typhus. A detailed history, demographic details, clinical features, complications, routine laboratory parameters and their relation with and without eschar was noted. Results: On analysis of demographic details, majority of scrub typhus patients belonged to Hilly district, Rudraprayag of Garhwal region. Common signs included fever (100\%), lymphadenopathy and splenomegaly (70\%), hepatomegaly (55\%), rash (37\%), eschar (35\%), meningitis $(20 \%)$, hepatitis and epistaxis (5\%), pleural effusion, sub-conjunctival hemorrhage and ARDS (2.5\%). Presence of eschar was strongly associated with abdominal pain, facial edema, meningitis and ARDS.Conclusion: Early diagnosis with high index of suspicion and timely treatment in children from hilly area with acute febrile illness decreases the mortality and leads to better prognosis.
\end{abstract}

Key words: Scrub typhus, Hilly area, Eschar, fever, Rash

\section{Introduction}

Scrub typhus also known as Bush typhus is the most important cause of acute febrile illness in South and East Asia and the Pacific. It is caused by bite of larval stage (chigger) of trombiculid mite belonging to Trombiculidae family, genus and subgenus Leptotrombidium, which serves as both vector and reservoir. The agent responsible in India is Orientia tsutsugamushi, which is an obligate intracellular gramnegative bacteria. Humans are the accidental host [1]. It affects all age group including children.

It was first described by Hajuku Hasimoto in 1810 as tsutsugamushi fever in people living on the banks of Shinano river and later by Baelz and Kawakami in1879 as Japanese flood fever [2-4]. Scrub typhus is predominantly distributed in the tsutsugamushi triangle, which is located over a very wide area of 13 million $\mathrm{km}$ bound by Japan in the east; China, Philippines, tropical Australia in the south; India, Pakistan and Tibet

Manuscript received: $5^{\text {th }}$ February 2019

Reviewed: $15^{\text {th }}$ February 2019

Author Corrected: $20^{\text {th }}$ February 2019

Accepted for Publication: $23^{\text {rd }}$ February 2019 in the west; Afghanistan and parts of the USSR in the north [5]. As many as one million people may be infected yearly in the disease endemic area [6]. In India, the first case of scrub typhus was reported in Himachal Pradesh in 1934[4]. Itexists in Himachal Pradesh, Jammu and Kashmir, Uttaranchal, Rajasthan, Assam, West Bengal, Maharashtra, Kerala, Tamil Nadu and Delhi $[7,8]$. It is predominant in scrubby terrain, forest and semi desert condition and more common during Augustto January [9].

The clinical manifestation vary in severity from mild and self limited to fatal and include fever, headache, inoculation eschar, rash,pneumonitis, pleural effusion, hepatomegaly, edema, acute kidney injury(AKI), acute respiratory distress syndrome (ARDS) and meningitis which occur approximately 10 days after the bite of chigger [6]. It is usually difficult to diagnose and if left untreated case fatality rate can go upto 30-35\% [10]. Howeverif the diagnosis is made on time, it can betreated easily. In India, Scrub typhus is grossly under diagnosed due to its nonspecific clinical presentation, 
limited awareness, lowindex of suspicion among clinicians and lack of diagnostic facilities. The main aim of our study was to analyze the epidemiology, clinical features, laboratory parameters and outcome of patients diagnosed with Scrub typhus and to compare these clinical features amongst those with or without eschar in pediatric population from Garhwal region of Uttarakhand. As there is paucity of data on Scrub typhus in Garhwal belt, so we conducted this study to bridge the lacunae of gap in understanding the features and outcome of scrub typhus.

\section{Methodology}

Type of study: Descriptive study conducted in Government Medical College and Hospital Srinagar Uttarakhand.

Sampling methods: A detailed history, demographic details, clinical features, complications, routine laboratory parameters were analysed on Excel spreadsheet. Other causes of fever such as malaria, dengue, enteric fever, urinary tract infection were ruled out by history, clinical examination and investigations such as haemogram, smear for malaria, dengue serology, widal, liver functions, renal functions, blood culture, chest radiograph, ultrasound and lumbar puncture.

In laboratory parameters, anaemia was considered when hemoglobin $(\mathrm{Hb})$ was $<10 \mathrm{mg} / \mathrm{dl}$, leukocytosis if total leucocyte count (TLC) was $>12000$ cells/cumm and leucopenia was defined as TLC $<4000$ cells/cumm. Thrombocytopenia was considered when platelet count was $<100,000$ cells/cumm, raised serum glutamic oxaloacetic transaminase (SGOT) was $>40 \mathrm{IU} / \mathrm{L}$, raised serum glutamate pyruvate transaminase (SGPT) was $>$ $35 \mathrm{IU} / \mathrm{L}$, raised bilirubin was $>2.5 \mathrm{mg} / \mathrm{dl}$ and raised urea $(>40 \mathrm{mg} / \mathrm{dl})$ and raised serum creatinine was $>1 \mathrm{mg} / \mathrm{dl}$.

Sample collection: Forty children who were ELISA positive for IgM Scrub typhus were enrolled in the study and hemogram, liver function test, blood urea and creatinine were done for these children. Other causes of fever with rash were excluded with haemogram, smear for malaria, dengue serology, widal, liver functions, renal functions, blood culture, chest radiograph, ultrasound and lumbar puncture.

Inclusion criteria: Children (below 18 years) with clinical features suggestive of Scrub typhus (fever, rash) who were ELISA positive for IgM

Exclusion criteria: Children with suspicion of scrub typhus who were not tested for Scrub typhus ELISA IgM were excluded.

Statistical method- Numerical data was analysed by descriptive statistics. Tests of significance were obtained for those with and without eschar for various clinical features and complications. Independentsamples $\mathrm{T}$ test was performed for continuous variables and they were expressed as mean and range. Chi square test, T test, Fischer's exact test and kruskalwallis test was performed for categorical data. Statistical significance was defined as $\mathrm{p}$ value $<0.05$.

Ethical consideration \& permission- Approval was taken from the Institutional Ethics Committee and a written informed consent was taken from parents or guardians.

\section{Results}

Forty children with scrub typhus of Garhwal region were enrolled in the study amongst which 22 were male and 18 were female. The age of children ranged between 2-12 years. 40\%(16) children belonged to Rudraprayag area, 22.5\% (9) belonged to Pauri, 20\%(8) belonged to Tehri, 15\% (6) belonged to Chamoli and 2.5\% (1) belonged to Gauchar (Graph 1).

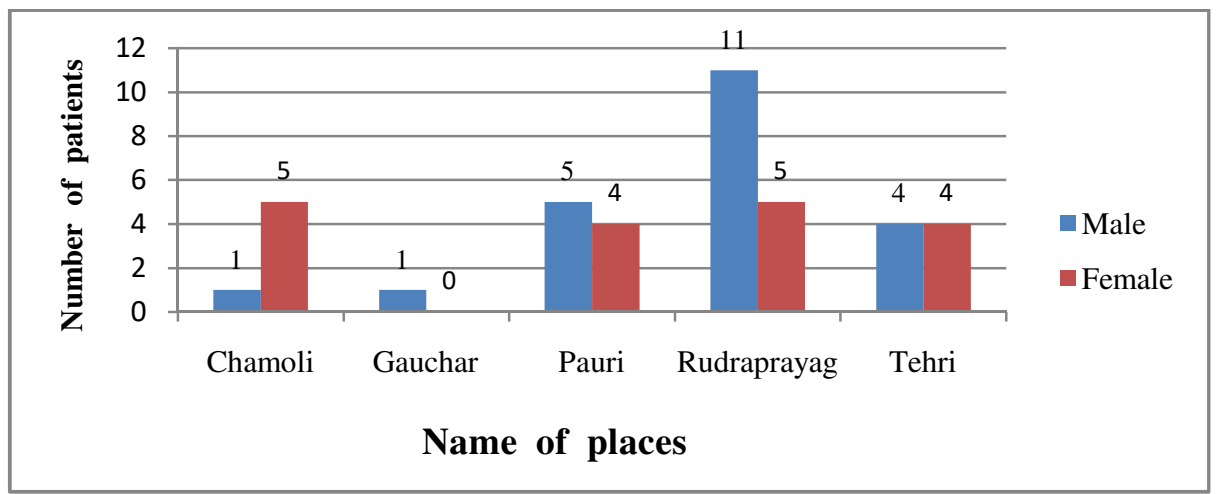

Graph 1-Area and sex wise distribution of scrub typhus 


\section{Original Research Article}

All children presented with fever. Cough was present in 35\% (14), rash which was predominantly seen in extremities was present in 37.5\% (15) and eschar in 35\% (14). Lymphadenopathy was seen in 70\%, headache in 57.5\%, vomiting in $52.5 \%$, abdominal pain in $40 \%$, sub conjunctival hemorrhage in $2.5 \%$, upper eyelid edema in $35 \%$, facial edema in $32.5 \%$, dyspnea and epistaxis in 5\%. Hepatomegaly in 55\%, splenomegaly in $70 \%$ and burning micturition in $17.5 \% .20 \%$ (8) developed meningitis, 5\% (2) developed hepatitis and 2.5\% (1) developed pleural effusion and ARDS. (Table 1)

Table-1: Clinical features and complications of patients with Scrub typhus.

\begin{tabular}{|l|c|}
\hline Clinical Feature(n=40) & Present \\
\hline Eschar & $14(35 \%)$ \\
\hline Lymphnodes & $28(70 \%)$ \\
\hline Headache & $23(57.5 \%)$ \\
\hline Vomiting & $21(52.5 \%)$ \\
\hline Rash & $15(37.5 \%)$ \\
\hline Abdominal pain & $16(40 \%)$ \\
\hline Subconjunctival hemorrhage & $1(2.5 \%)$ \\
\hline Upper eyelid edema & $14(35 \%)$ \\
\hline Facial edema/puffiness of face & $13(32.5 \%)$ \\
\hline Dyspnea & $2(5 \%)$ \\
\hline Hepatomegaly & $22(55 \%)$ \\
\hline Splenomegaly & $28(70 \%)$ \\
\hline Burning micturation & $7(17.5 \%)$ \\
\hline Epistaxis & $2(5 \%)$ \\
\hline Meningitis & $8(20 \%)$ \\
\hline ARDS & $1(2.5 \%)$ \\
\hline Pleural effusion & $1(2.5 \%)$ \\
\hline Hepatitis Bilirubin $>2.5 \mathrm{mg} / \mathrm{dl}$ & $2(5 \%)$ \\
\hline
\end{tabular}

Mean $\mathrm{Hb}$ was $10.57 \mathrm{~g} / \mathrm{dl}$ with range between $6.9 \mathrm{~g} / \mathrm{dl}-14 \mathrm{~g} / \mathrm{dl}$. Anaemia was seen in 12 patients, mean TLC was 8505.25 cells/cumm (range-1200 cells/cumm-17700 cells/cumm). Leucocytosis was present in 10\% (4) and leucopenia in $2.5 \%$ (1) patient. The mean percentage of polymorphonuclear neutrophils was 63.3 (range-43-82) and of lymphocytes was 33.62 (range-12-52). Mean platelet count was 1.88 lakh/cumm (range-1lakh-3.1lakh). None of them had thrombocytopenia. Hepatic involvement in the form of raised SGPT was seen in $82.5 \%$ (33) and raised SGOT in 50\% (20) patients. Mean bilirubin was $0.828 \mathrm{mg} / \mathrm{dl}$ (range is $0.2 \mathrm{mg} / \mathrm{dl}-2.7 \mathrm{mg} / \mathrm{dl}$ )and amongst which $5 \%$ patients had hepatitis. Pulmonary involvement was manifested in the form of cough in 35\%, dyspnea in 5\%, pleural effusion and ARDS in $2.5 \%$ of patients. $7.5 \%$ patients had abnormal chest radiograph. Renal involvement was seen in the form of burning micturition in $17.5 \%$, increased urea in $20 \%$ and increasedcreatininein $5 \%$ (Table 2).

Table-2: Laboratory parameters of patients with Scrub typhus.

\begin{tabular}{|c|c|c|c|}
\hline $\begin{array}{l}\text { Laboratory test and their } \\
\text { normal range }\end{array}$ & $\begin{array}{l}\text { Range in patients } \\
\text { with scrub typhus }\end{array}$ & Mean & $\begin{array}{l}\text { Percentage of children } \\
\text { with abnormal value }\end{array}$ \\
\hline Hemoglobin $>10 \mathrm{~g} / \mathrm{dl}$ & $6.9-14$ & $10.57 \mathrm{~g} / \mathrm{dl}$ & $\downarrow$ in $12(30 \%)$ \\
\hline TLC(4000-12000 cells/cumm) & $1200-17700$ & 8505.25 cells/cumm & $\uparrow$ in $4(10 \%)$ \\
\hline Platelet(1lakh-3.1lakh) & 1lakh-3.1lakh & $1.88 \mathrm{lakh} / \mathrm{cumm}$ & $\downarrow$ in 0 \\
\hline Blood urea $(<40 \mathrm{mg} / \mathrm{dl})$ & $14 \mathrm{mg} / \mathrm{dl}-76 \mathrm{mg} / \mathrm{dl}$ & $32.5 \mathrm{mg} / \mathrm{dl}$ & $\uparrow$ in $8(20 \%)$ \\
\hline Serum creatinine $(<1 \mathrm{mg} / \mathrm{dl})$ & $0.2 \mathrm{mg} / \mathrm{dl}-1.2 \mathrm{mg} / \mathrm{dl}$ & $0.615 \mathrm{mg} / \mathrm{dl}$ & $\uparrow$ in $2(5 \%)$ \\
\hline Total bilirubin $(<2.5 \mathrm{mg} / \mathrm{dl})$ & $0.2 \mathrm{mg} / \mathrm{dl}-2.7 \mathrm{mg} / \mathrm{dl}$ & $0.828 \mathrm{mg} / \mathrm{dl}$ & $\uparrow$ in $2(5 \%)$ \\
\hline SGOT $(<40 \mathrm{IU} / \mathrm{l})$ & 14IU/1-200IU/1 & $45.58 \mathrm{IU} / 1$ & $\uparrow$ in $20(50 \%)$ \\
\hline SGPT $(<35 \mathrm{IU} / 1)$ & 24IU/1-331IU/1 & $45.58 \mathrm{IU} / 1$ & $\uparrow$ in $33(82.5 \%)$ \\
\hline
\end{tabular}

Blood and urine cultures, widal, smear for malaria, cerebrospinal fluid examination which were all normal were done to rule out other causes. 


\section{Original Research Article}

We compared patients with and without eschar with regards to their clinical features (Table 3). The meanage of those with an eschar was 9.5 years compared to 7.5 years in those withoutan eschar $(p<0.005)$. Abdominal pain $(p 0.021)$, facial edema ( $p$ 0.031) and meningitis ( $\mathrm{p}$ 0.014) were more common in those with an eschar, whereas headache ( $\mathrm{p} 0.048)$ was less common in those with an eschar. ARDS and hepatitis was also seen in those with an eschar (Table 3).

Table-3: Comparison of clinical features in those with or without eschar in children of scrub typhusa-kruskal wall, b-T test, c-Chi square, d-Fischer exact.

\begin{tabular}{|c|c|c|c|}
\hline Parameters & $\operatorname{Eschar}(n=14)$ & No Eschar $(n=26)$ & P value \\
\hline Age in years-Mean & 9.5 & 7.5 & $0.005^{\mathrm{a}}$ \\
\hline Fever:n (mean duration) & $14(8.21)$ & $26(7.58)$ & $0.593^{\mathrm{b}}$ \\
\hline Cough: $\mathrm{n}$ (mean duration) & $3(2.64)$ & $11(2.65)$ & $0.978^{\mathrm{b}}$ \\
\hline Rash: n (\%) & $7(50 \%)$ & $8(30.8 \%)$ & 0.231 \\
\hline Headache: $\mathrm{n}(\%)$ & $11(78.6 \%)$ & $12(46.2 \%)$ & $0.048^{\mathrm{c}}$ \\
\hline Vomiting: n (\%) & $9(64.3 \%)$ & $12(46.2 \%)$ & $0.273^{\mathrm{c}}$ \\
\hline Abdominal pain: $\mathrm{n}(\%)$ & $9(64.3 \%)$ & $7(26.9 \%)$ & $0.021^{\mathrm{c}}$ \\
\hline Lymphnodes: $\mathrm{n}(\%)$ & $12(85.7 \%)$ & $16(61.5 \%)$ & $0.112^{\mathrm{c}}$ \\
\hline Facial edema: $n(\%)$ & $8(57.1 \%)$ & $5(19.2 \%)$ & $0.031^{\mathrm{d}}$ \\
\hline Upper eyelid edema: $\mathrm{n}(\%)$ & $7(50 \%)$ & $7(26.9 \%)$ & $0.178^{\mathrm{d}}$ \\
\hline Subconjunctival hemorrhage: $\mathrm{n}(\%)$ & $1(7.1 \%)$ & 0 & \\
\hline Dyspnea: $\mathrm{n}(\%)$ & $1(7.1 \%)$ & $1(3.8 \%)$ & $1^{\mathrm{d}}$ \\
\hline Epistaxis: n (\%) & 0 & $2(7.6 \%)$ & \\
\hline Burning micturition: $\mathrm{n}(\%)$ & $4(28.4 \%)$ & $3(11.4 \%)$ & \\
\hline Hepatomegaly: n (\%) & $11(78.6 \%)$ & $11(42.3 \%)$ & $0.028^{\mathrm{c}}$ \\
\hline Splenomegaly: n (\%) & $11(78.6 \%)$ & $17(65.4 \%)$ & $0.484^{\mathrm{d}}$ \\
\hline Meningitis: $\mathrm{n}(\%)$ & $6(42.9 \%)$ & $2(7.7 \%)$ & $0.014^{\mathrm{d}}$ \\
\hline ARDS: $\mathrm{n}(\%)$ & $1(7.1 \%)$ & 0 & \\
\hline Hepatitis: n (\%) & 1 & 1 & \\
\hline
\end{tabular}

\section{Discussion}

In this descriptive study, we describe the profile of scrub typhus in children of Garhwal region. Males were more affected than females which is probably due to higher exposure of males to outdoor games [11-13].The mean age of presentation was $8.15 y$ ear, which was similar to that of the previous reported study [11].The clinical features of scrub typhus in children are nonspecific and are often misdiagnosed. All the patients had high grade continuous fever as reported by other authors [11-14]. The hallmark of scrub typhus is rash, it is neither seen at presentation nor is it necessary that it will be present in all patients [7].

Unlike Digra et al [13] who reported rash in $100 \%$ patient, in our study rash was seen in only $37.5 \%$ patients which was similar to other studies [12,14,15]. Although, eschar is an important sign in the diagnosis of scrub typhus, its absence does not rule out the disease. In our study, eschar was seen in $35 \%$, which was comparable to those of other studies $[11,12,14,15]$ where as Digra et al[13], did not report eschar in any of their cases. This may be due to variation of strain of the organism in different location. Other complains noted in this study were headache, vomiting and abdominal pain which were seen in $57.5 \%, 52.5 \%$ and $40 \%$ respectively. Bhat et al [11] noted them in $18 \%, 56 \%$ and $33 \%$ and Khan et al [14] noted them in $45 \%, 45 \%$ and $26 \%$ respectively. Tender lymphadenopathy which is the most consistent finding of scrub typhus was noted in $70 \%$ patients of our study whereas other studies from Uttarakhand have reported it to lesser extent $[11,12,14]$ and Rakholia et al[16] have not reported any case of lymphadenopathy.

Facial puffiness was seen in $32.5 \%$, upper eyelid edema in $35 \%$, none of our patient had pedal edema whereas Bhat et al[11] observed facial puffiness and pedal edema in 52\% and 39\% respectively and Digra et al[13] noted that 57.14\% had edema and amongst them 6 had facial puffinessand 3 had pedal edema and anasarca respectively. Ocular involvement in scrub typhus is common but as it is frequently asymptomatic, it is often overlooked. The external ocular changes in scrub typhus are conjunctival congestion, subconjunctival 
hemorrhage. In this study we had 1 patient with subconjunctival hemorrhage, none of our patient had conjunctival congestion where as Digra et al[13] noted conjunctival congestion in $47.6 \%$ patients and there was no evidence of ocular involvement in other studies of Uttarakhand $[11,12,14,16]$. Hemorrhagic symptoms in scrub typhus may range from epistaxis to more severe bleeds [17]. We had 5\% cases of epistaxis without thrombocytopenia in this study on the contrary there were no cases of epistaxis in other studies $[11,12,14,16]$. We observed gastrointestinal involvement in the form of hepatomegaly in 55\% and splenomegaly in $70 \%$ cases whereas Bhat et al[11]noted hepatomegaly and splenomegaly in $82 \%$ and $59 \%$ respectively and Jain et al [12] had a lesser rate of $26.3 \%$ both.

Scrub typhus is a life threatening disease in children. Serious complications usually occur in the second week of illness, which include ARDS, pneumonia, pleural effusion, meningitis, renal dysfunction and myocarditis.Aseptic meningitis which was noted in $20 \%$ cases was the most common complication observed in the present study followed by hepatitis in 5\% cases and least observed was ARDS and pleural effusion.

However, unlike Bhat et al [11] cardiovascular complications and renal involvement were not seen. Bhat et al [11] had a higher rate of complications as compared to our study. They observed meningitis in $30.3 \%$, hepatitis in $13.6 \%$, ARDS in $12.1 \%$ and pleural effusion in $9.1 \%$, in addition to these they noted myocarditis and acute kidney injury also.

Laboratory investigations help in differentiating aetiology of fever, which is important in developing countries like India where there are limited resources. In our study, anemia was seen in $30 \%$ patient whereas Rakholia et al [16] noted it in $69.23 \%$ patients. $10 \%$ patients had leucocytosis which was comparable to Rakholia et al [16] whereas Jainet al [14] noted it in much higher population of $47.36 \%$. We did not had any case of thrombocytopenia. On the contrary, other authors noticed thrombocytopenia in $68.42 \%$ [14] and $92.3 \%$ [16].

This variation could be due to different cut off limit used in different studies. We found hepatic involvement in the form of raised SGPT in $82.5 \%$, raised SGOT in $50 \%$ and hepatitis in 5\% patients. Jain et al [14] observed it in $73.68 \%$ and $54.26 \%$ patients. On the contrary, Rakholia et al [16] had hepatitis in $69.23 \%$ patients and raised SGOT and SGPT in all their patients. We had renal involvement in $20 \%$ patients which was comparable to Rakholia et al [16]. In this study, eschar was present more in males $(27.5 \%)$ as compared to females $(7.5 \%)$ which was similar to Rose et al [18] who also had male preponderance. Mean age of children with eschar was 9.5 year and without eschar was 7.5 year. Rose et al [18] had mean age of 5 year and 7 year respectively. In our study, there was strong associationbetween the presence of an eschar and abdominal pain, facial edema, meningitis and ARDS where as absence of eschar was associated with headache. Hepatomegaly was common in both groups.

Incontrast to our observations, Rose et al [18] found significant association between the presence of an eschar and breathing difficulty, ARDS and thrombocytopenia, whereas absence of eschar was associated with meningitis. As far as outcome and mortality were concerned, just like Rakholia et al[16], we reported a favorable outcome and there was no mortality and morbidity which could be due to timely diagnosis with good supportive care. The limitation of our study was that it was conducted at a tertiary referral hospital; it does not represent the entire community, so the actual incidence may be higher. Despite the limitation, we tried to increase the awarenessof this treatable disease, so that it may provide a better understanding of the clinical manifestations and complication of scrub typhus in children.

Hence to conclude, it is recommended that if a child of hilly area presents with acute febrile illness, maculopapular rash, the possibility of scrub typhus should be kept in mind. Early empirical antibiotic therapy should be considered for these patients, as delay in treatment would result in life threatening complications. General practitioner should be made aware of the same for managing these patients at primary care centre.

What This Study Adds- We tried to create awareness about the varied clinical presentation of scrub typhus which all practitioner should keep in mind. Presence of eschar is not necessary for the diagnosis of scrub typhus. Timely diagnosis and early empirical treatment is must for improving the survival rate of the scrub typhus patient.

\section{Contribution by different authors}

1. Dr Vyas Rathore- Data collection and enrollment of the subjects

2. Dr Ayesha Imran- Preparation of manuscript as a whole

3. Dr Monika Pathania- Grammatical editing

4. Dr Gowhar Wani- Statistics and analyses of data

5. Dr Anumodhan Gupta- Formatting the manuscript 


\section{Original Research Article}

Acknowledgement- We are thankful to Dr. Anand Jain and Dr Rohit Chib for the support in conducting this study.We are also thankful to Department of Microbiology and Pathology of Veer Chandra Singh Garhwali Government Medical Sciences and Research institute for the laboratory support.

\section{Abbreviations}

AKI- Acute kidney injury.

ARDS- Acute respiratory distress syndrome.

Hb- Hemoglobin.

TLC- Total leucocyte count.

SGOT-Serum glutamic oxaloacetic transaminase.

SGPT- Serum glutamate pyruvate transaminase.

Funding: Nil, Conflict of interest: None initiated, Perission from IRB: Yes

\section{References}

1. Watt G, Parola P. Scrub typhus and tropical rickettsioses. Curr Opin Infect Dis. 2003 Oct;16(5):42936. DOI:10.1097/01.qco.0000092814.64370.70

2.Harden VA. Typhus, Scrub (Tsutsugamushi). In: The Cambridge World History of Human Disease Kiple KF, editor. Cambridge University Press. 1993;153:355-356.

3. Parola P, Raoult D. Tropical rickettsioses. Clin Dermatol. 2006 May-Jun; 24 (3):191-200. DOI:10. 1016/j. clindermatol.2005.11.007

4. Oaks JSC, Ridgway RL, Shirai A, Twartz JC. Scrub typhus. Bulletin No 21 United States Army Medical Research Unit, Institute for Medical Research, Malaysia 1983; 1-107.

5. Kelly DJ, Richards AL, Temenak J, et al. The past and present threat of rickettsial diseases to military medicine and international public health. Clin Infect Dis. 2002 Jun 15; 34 (Suppl 4):S145-69. DOI: 10. 1086/ 339908

6. RoultD Scrub typhus. In:, Mandell GL, Bennett JE, Dolin R,editors. Principles and Practice of Infectious Diseases. $6^{\text {th }}$ ed. Philadelphia: Churchill Livingstone; 2004. p.2309-10.

7. Rathi N, Rathi A. Rickettsial infections: Indian perspective. Indian Pediatr. 2010 Feb;47(2):157-64.
8. Mahajan SK. Scrub typhus. J Assoc Physicians India. 2005 Nov;53:954-8.

9. Kamarasu K, Malathi M, Rajagopal V, et al. Serological evidence for wide distribution of spotted fevers \& typhus fever in Tamil Nadu. Indian J Med Res. 2007 Aug;126(2):128-30.

10. Batra HV. Spotted fevers \& typhus fever in Tamil Nadu. Indian J Med Res. 2007 Aug;126(2):101-3.

11. Nowneet Kumar Bhat, Minakshi Dhar, Garima Mittal et al.Scrub Typhus in Children at a Tertiary Hospital in North India: Clinical Profile and Complications. Iran J Pediatr. 2014 Aug;24(4):387-92

12. Neeraj Jain, Vibha Jain. Study on Clinico Laboratory Profile of Children with Scrub Typhus. J. Nepal Paediatr. Soc. 2012;32(2):187-92

13. Sanjeev Kumar Digra, GhanShyam Saini, Virender Singh et al. Scrub Typhus in Children. Jammu Experience. JK Science.2010;12(2):95-97

14. Fauzia Khan, Garima Mittal, R K Agarwal et al. Prevalence of Scrub Typhus A Cause of concern in Uttarakhand Region, India.Int.J.Curr.Microbiol. App. Sci 2015 (Special Issue-1):101-9

15. Palanivel S, Nedunchelian K, Poovazhagi V, et al. Clinical profile of scrub typhus in children. Indian $\mathrm{J}$ Pediatr. 2012 Nov;79(11):1459-62. doi: 10.1007/s 12098- 012- 0721-0. Epub 2012 Feb 29.

16. RituRakholia, Vinita Rawat, Preeti Chaturvedi. Scrub typhus Meningoencephalitis in children from a Tertiary care centre, Uttarakhand, India. Ann Med Health Sci Res.2017;7:388-92

17. Rashna Dass, Nayan Mani Deka, Sourabh Gohain Duwarah et al. Characteristics of Pediatric Scrub Typhus during an outbreak in the North Eastern Region of India: Peculiarities in clinical presentation, Laboratory findings and complications.Indian J Pediatr. 2010;78(11):1365-70

18. Rose W, Rajan RJ, Punnen A, et al. Distribution of Eschar in Pediatric Scrub Typhus. J Trop Pediatr. 2016 Oct;62(5):415-20. doi: 10.1093/tropej/fmw027. Epub 2016 Apr 27.

\section{How to cite this article?}

Rathore V, Imran A, Pathania M, Wani G, Gupta A. A study on clinico- laboratory parameters of children with scrub typhus in Garhwal region of Himalayan belt. Int J Pediatr Res. 2019;6(02):91-96. doi:10.17511/ijpr.2019.i02.09 